DOI: https://doi.org/10.36910/6775-2524-0560-2021-45-06

УДК 658.512:65.011.56

Троянчук Богдана Віталіївна, студентка

https://orcid.org/0000-0002-8352-2829

Федік Леся Юріївна, к.т.н., доцент

https://orcid.org/0000-0003-2555-4205

Луцький національний технічний університет

\title{
ВИКОРИСТАННЯ САПР У ПРОЕКТУВАННІ СИСТЕМ АВТОМАТИЗАЦЇ̈
}

Троянчук Б.В., Федік Л.Ю. Використання САПР у проектуванні систем автоматизації. У статті визначено і досліджено актуальні системи автоматизованого проектування. А також проаналізовано існуючі CAD системи $\mathrm{i}$ спрогнозовано розвиток ринку в цій сфері. Викладено особливості проектування систем автоматизації в програмах AutoCAD, Solidworks, LibreCAD, MagiCAD, ZWCAD.

Ключові слова: проектування, система, автоматизація, програма, САПР, CAD, оцінка, аналіз.

Троянчук Б.В., Федик Л.Ю. Использование САПР при проектировании систем автоматизации. В статье определены и исследованы актуальные системы автоматизированного проектирования. А также проанализированы существующие $\mathrm{CAD}$ системы и спрогнозировано развитие рынка в этой сфере. Изложены особенности проектирования систем автоматизации в программах AutoCAD, Solidworks, LibreCAD, MagiCAD, ZWCAD.

Ключевые слова: проектирование, система, автоматизация, программа, СAПР, CAD, оценка, анализ.

Troyanchuk B.V., Fedik L.Yu. The use of CAD systems in the design of automation systems. The article identifies and investigates current computer-aided design systems. Also, the existing CAD systems were analyzed and the development of the market in this area was predicted. The features of the design of automation systems in AutoCAD, Solidworks, LibreCAD, MagiCAD, ZWCAD are outlined.

Key words: design, system, automation, program, CAD, CAD, assessment, analysis.

Постановка проблеми. Сьогоднішні завдання проектування породжують нові програми. Серед великої чисельності, подекуди важко обрати найвідповіднішу. У цій статті будуть проаналізовані CAD системи, які користуються популярністю серед інженерів для проектування систем автоматизації.

Аналіз останніх досліджень та публікацій. Дослідження консалтингової компанії “Grand View Research" про розвиток 3D CAD.

Невирішені раніше частини загальної проблеми. Відсутність аналізу про найкращу САПР систему для проектування систем автоматизації.

Мета статті: визначити та дослідити актуальні системи автоматизованого проектування та зробити висновки їх ефективності. цій сфері.

Постановка завдання: проаналізувати існуючі CAD системи, спрогнозувати розвиток ринку в

Об'єкт дослідження: AutoCAD, Solidworks, LibreCAD, MagiCAD, ZWCAD.

Предмет дослідження: ступінь релевантності обраних систем автоматизованого проектування i розрахунку.

Виклад основного матеріалу. Основними стадіями проектування систем автоматизації є формування вимог до автоматизованих систем, розробка концепції автоматизованих систем, технічні завдання, ескізний проект, технічний проект, робоча документація і супроводження автоматизованих систем.

Тому доцільним є застосування CAD (Computer Aided Design - автоматизоване проектування) систем під час проектування. За якого окремі перетворення описів об’єкта, алгоритму функціонування або алгоритму процесу його створення, здійснюються у взаємодії людини й комп'ютера. Графічні особливості CAD застосовуються в проектуванні й виробництві електроніки, будівельних конструкцій, машин і механізмів [Ошибка! Источник ссылки не найден.].

CAD система має у своєму складі такі складові частини: конструкторську, технологічну, архітектурно-будівельну, кошторисну частини, а також системи: санітарно-технічну, електротехнічну і автоматизації та гідротехнічні спорудження.

Історія походження перших «електронних кульманів» почалася від Патріка Ганратті, якого називають «батьком CAD/CAM». Він став розробником PRONTO (програми для операцій 3 числовими інструментами) першої системи програмування з ЧПК у 1957 році. Насправді, деякі галузеві аналітики підрахували, що 70\% усіх тривимірних механічних CAD/CAM систем, доступних сьогодні мають їх коріння до оригінального коду розробника. А послідовником був Айвен Сазерленд що розробив Sketchpad у 1963 році як частину своєї дисертації в Массачусетському технологічному

(C) Троянчук Б.В., Федік Л.Ю. 
інституті під назвою «Sketchpad, A Man-Machine Graphical Communication System». Користувачі могли взаємодіяти з програмою через екран, світлове перо для чернетки та набір кнопок для встановлення параметрів або обмежень [2].

AutoCAD відноситься до софту, який випускається компанією Autodesk з 1982 року. Спочатку він був розроблений для використання на Windows, 3 підтримкою 32-, та 64-розрядних систем, а 3 2013 року став доступний на MAC OS. Зараз він перекладений на 18 мов і випущені мобільні застосунки для Android, iPad i iPhone.

Для спрощення 2D проектування в програмі існують такі інструменти: інтелектуальне нанесення розміру, видові екрани, хмари для поміток, зв'язування відомостей, експорт з Microsoft Excel.

Система може експортувати інформацію з 3D принтерів під час 3D моделювання. B останніх версіях не потрібно завантажувати весь макет у пам'ять, через змогу кешування взаємодійної області і запропоновано чимало розширень для обміну: dwg, dxf, dwt, dws, pdf.

Автокад має у своєму складі такі інструментарії як: Architecture, Mechanical, Map 3D, MEP, Electrical, Plant 3D, Raster Design. Блоки яких наведені на рис. 1.

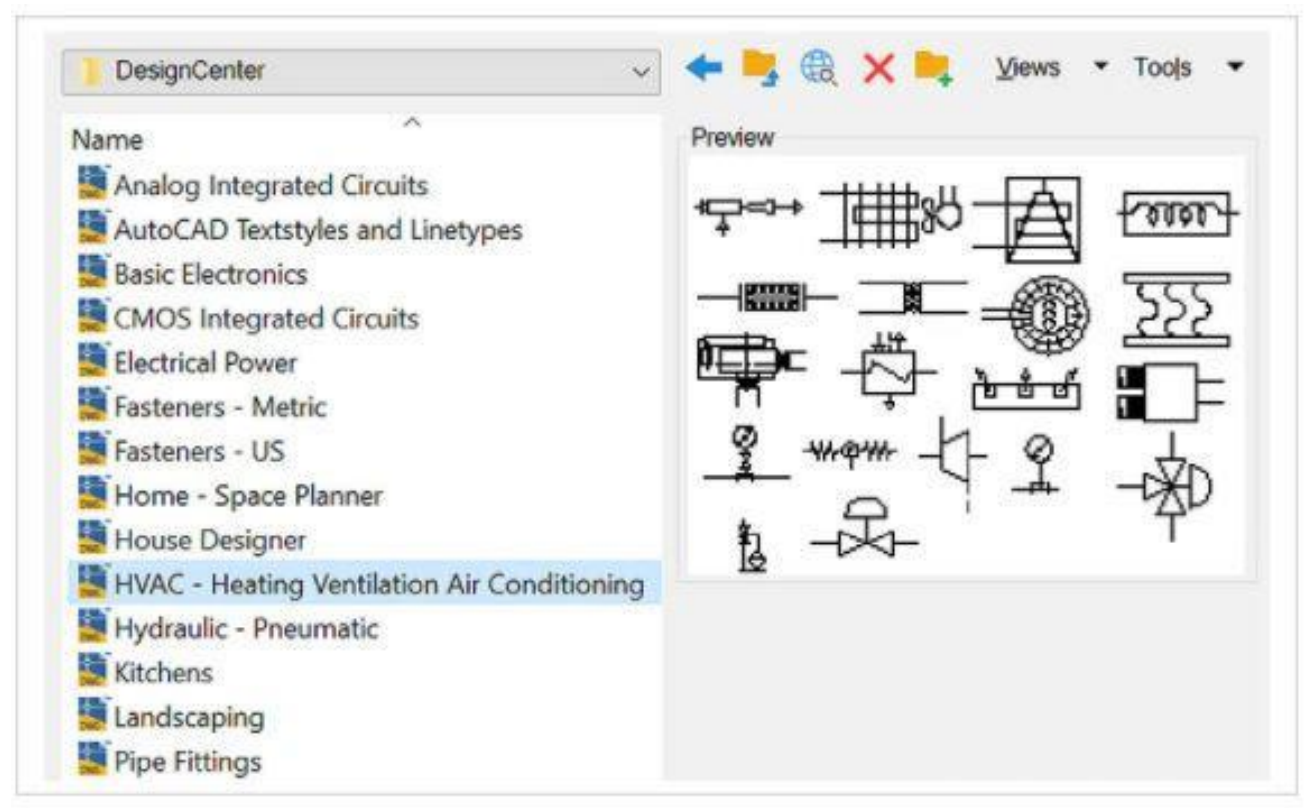

Рис. 1. Блоки AutoCAD

Дана система CAПР дозволяє створити власні блоки чи вибрати готові p AutoCAD та AutoCAD LT. Зокрема, вставити блок у креслення, вказавши файл креслення або визначити блок у файлі креслення. Потім його можна легко перемістити, скопіювати, повернути або масштабувати [3].

Для проектування систем автоматизації застосовують також програму SolidWorks. A саме: для моделювання твердих тіл, що використовує параметричний, заснований на ознаках, підхід до створення моделі.

Це програмне забезпечення розробив випускник Массачусетського технологічного інституту Джон Гірштік у 1995 році, який заснував компанію SolidWorks Corporation. Воно включає інструменти моделювання, що дозволяють керувати проектами в реальному часі, тобто інтегровану систему автоматизованого моделювання та процес проектування.

Окрім розглянутих програм застосування знайшла програма MagiCAD. Вона автоматизовує велику кількість працемістких завдань у проектуванні інженерних систем, включаючи створення та редагування стандартних з'єднань, обводів повітроводів та труб, вертикальних переходів, а також складніших з'єднань, таких як: з'єднання горизонтальних елементів під кутом, труб та радіаторів, труб та змішувачів, створення ексцентричних переходів та ін. Програма дозволяє креслити повітроводи і трубопроводи відразу з використанням серій ізоляції з легко змінюваними розмірами.

У MagiCAD проектування від початку ведеться 3 використанням реально існуючого обладнання. Якщо потрібний клапан, радіатор, вентиляційні грати або будь-який інший об'єкт, його можна вибрати 3 найбільшої в Європі бази обладнання та компонентів, моделі яких перевірені та схвалені виробниками. 
MagiCAD підтримує багато національних стандартів і символів, що робить його унікальним. Програма містить у своєму складі такі модулі як: вентиляція, трубопроводи, електропостачання, схеми, спринклери, опори і підвіски, велика бібліотека реального обладнання, інструменти координації, інтегровані розрахунки, локалізація, інструменти проектування, плагіни та інструменти підбору обладнання, рис. 2. А також представлено понад 1000000 ВІМ-об'єктів провідних світових виробників [4].

Зокрема модуль «Трубопроводи» призначений для проектування та розрахунку систем опалення, тепло- та холодопостачання, водопостачання, каналізації, спринклерних та інших систем. У роботі використовуються ті самі команди незалежно від того, яка система проектується. Цей модуль поєднує в собі зручний креслярський інструмент та потужне розрахункове ядро [5].

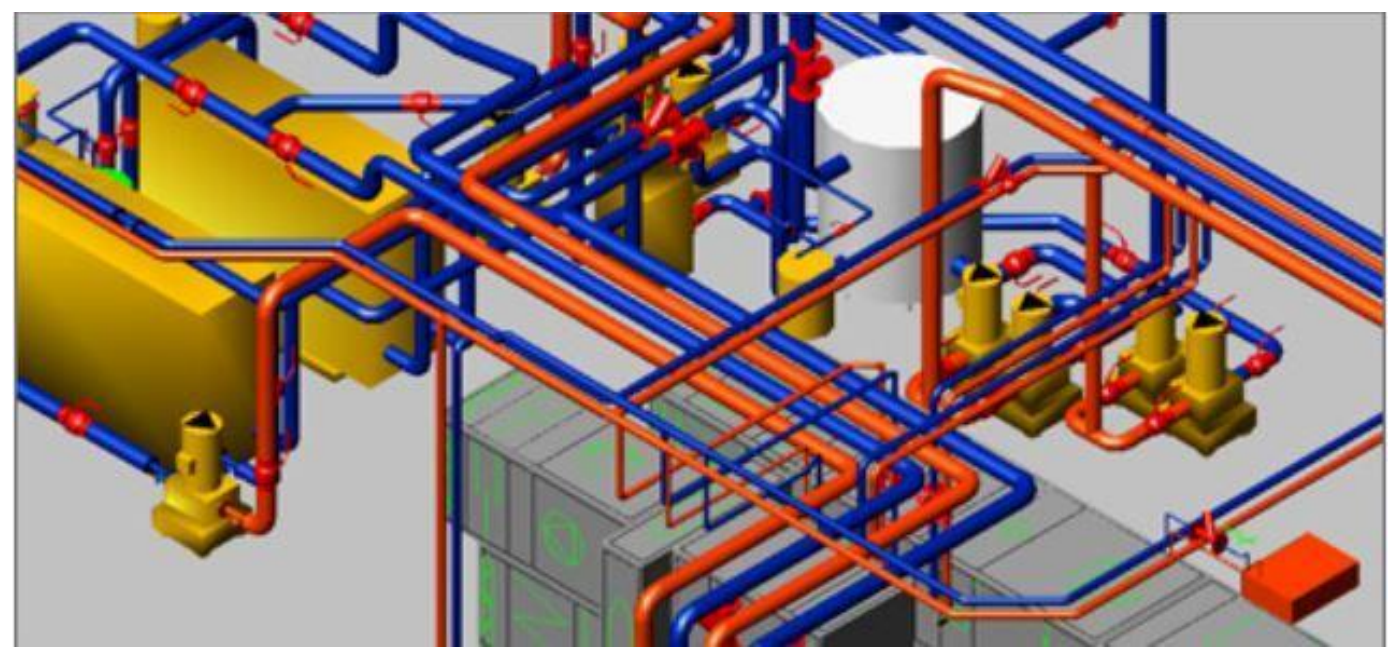

Рис. 2. MagiCAD Трубопроводи

У MagiCAD система проектної документації для будівництва, GraphiCS, дозволяють працювати 3 мережевою базою даних та розмежовувати права доступу користувачів до перегляду, редагування та публікації об'єктів [6].

На рис. 3 проілюстрований комплекс інструментів для інженерних мереж, який дозволяє формувати розведення внутрішніх комунікацій на плані. Побудова інженерних мереж реалізована функціоналом конекторів, обладнання та трас. Зокрема у базу даних включені шаблони трас, обладнання та конектори, що призначені для оформлення креслень вентиляції та внутрішнього газопостачання. Стандартна версія програми містить понад 3000 параметричних будівельних об'єктів (елементів бази даних): балки, колони, ригелі, плити перекриттів, фундаментні блоки, палі, металопрокат, кріплення та ін. За замовчуванням база знаходиться під керуванням СУБД PostgreSQL.

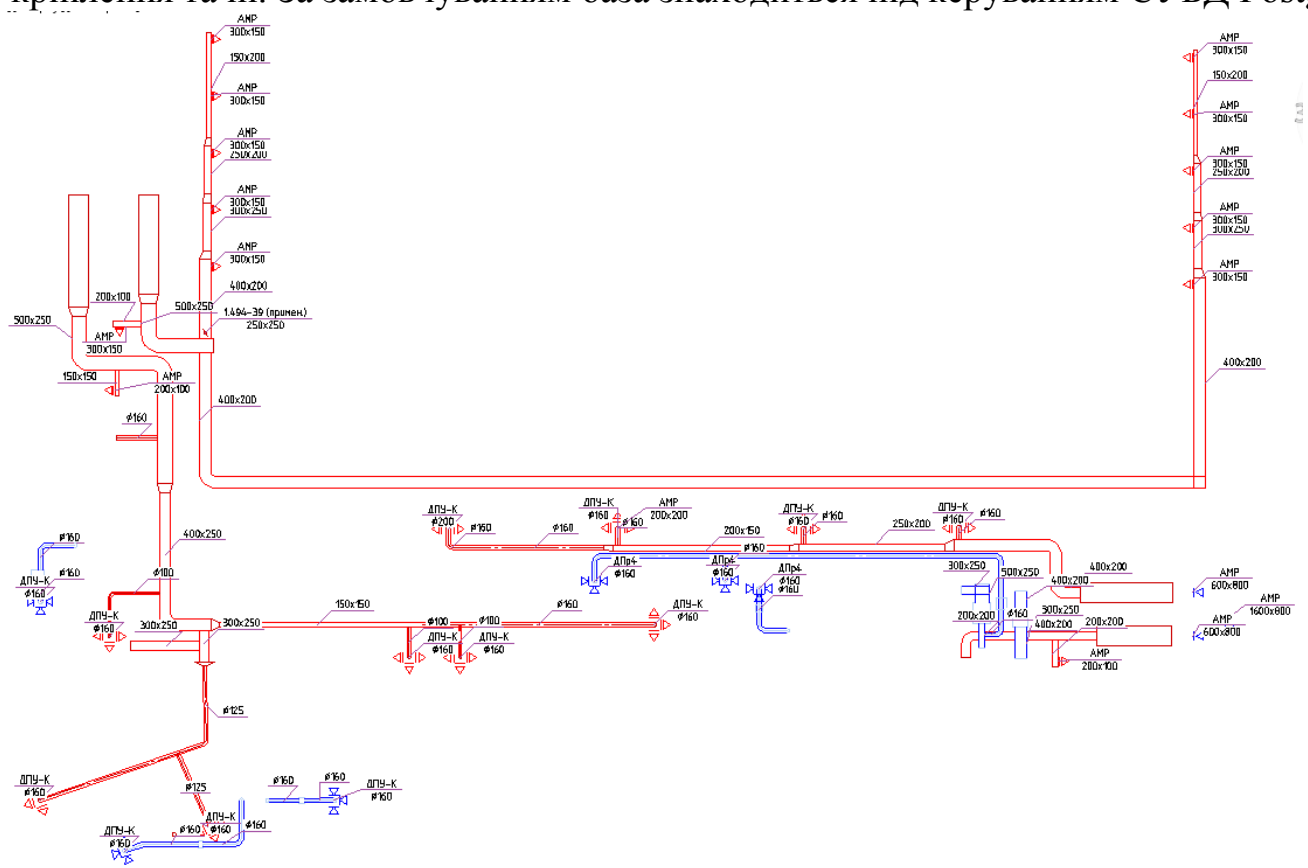

Рис. 3. Інженерні комунікації в MagiCAD

(C) Троянчук Б.В., Федік Л.Ю. 
Окрім розглянутих засобів проектування систем автоматизації застосовується також LibreCAD (раніше CADuntu). Ця програма являє собою крос-платформну та вільну САПР для 2D креслення та проектування, що створена на основі QCAD, рис. 4. Вона має власний формат файлів під назвою $\mathrm{DXF}$, який спочатку розроблявся для обміну файлами з пакетом AutoCAD. A також можливість імпортувати та експортувати файли у форматах SVG, PDF, BMP, PPM, PNG, XPM, XBM. LibreCAD локалізована на безліч мов, які можна додатково завантажити та встановити з Інтернету $[7,8]$.

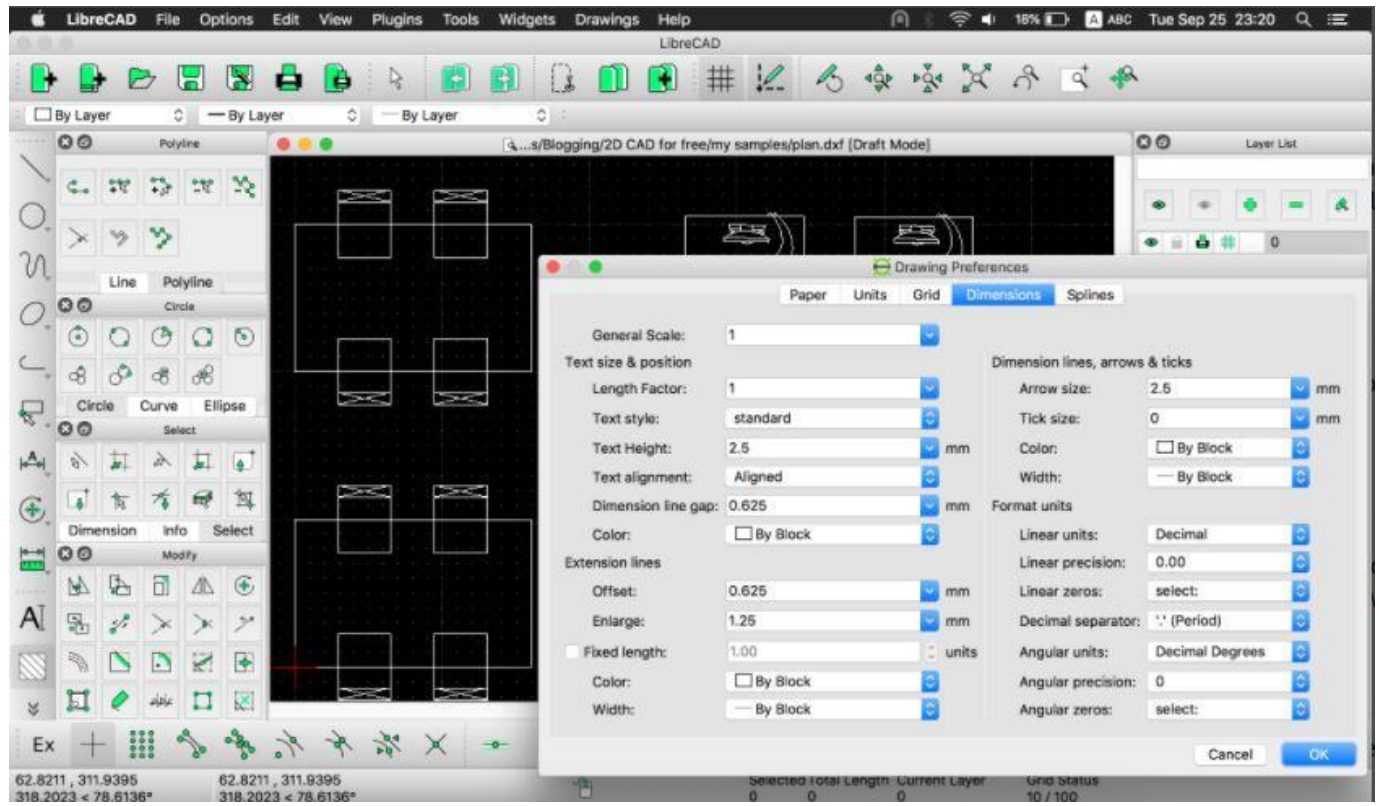

Рис. 4. LibreCAD та його налаштування

Для оцінки тенденцій та потреб сучасних проектних компаній скористаємося аналізом американської дослідницької та консалтингової компанії - “Grand View Research", яка має понад 20 років досвіду досліджень багатьох регіонів та країн (Північна та Південна Америка, Свропа, СНД та ЦСЄ (в тому числі, Україна), Близький Схід та Африка, Азія). Згідно нього широке застосування отримала хмарна платформа для програмного забезпечення 3D CAD. Найбільшою перевагою іiі $\epsilon$ отримання доступу до власних проектів з різних пристроїв у різних куточках світу, що сприяє розвитку ринку і $є$ безперечним плюсом для сучасної епідеміологічної ситуації у світі (Covid-19).

Так на рис. 5 представлений графік статистичних і прогностичних даних цієї компанії з 2016 до 2028 року, ринку програмного забезпечення для 3D CAD в США. Двоколірні стовпці показують відповідно рівень локального та хмарного програмного забезпечення. Аналіз рисунку показує, що зі зростанням технології 3D-друку виготовлятиметься широкий асортимент виробів із різноманітних матеріалів залежно від потреб користувачів [9].

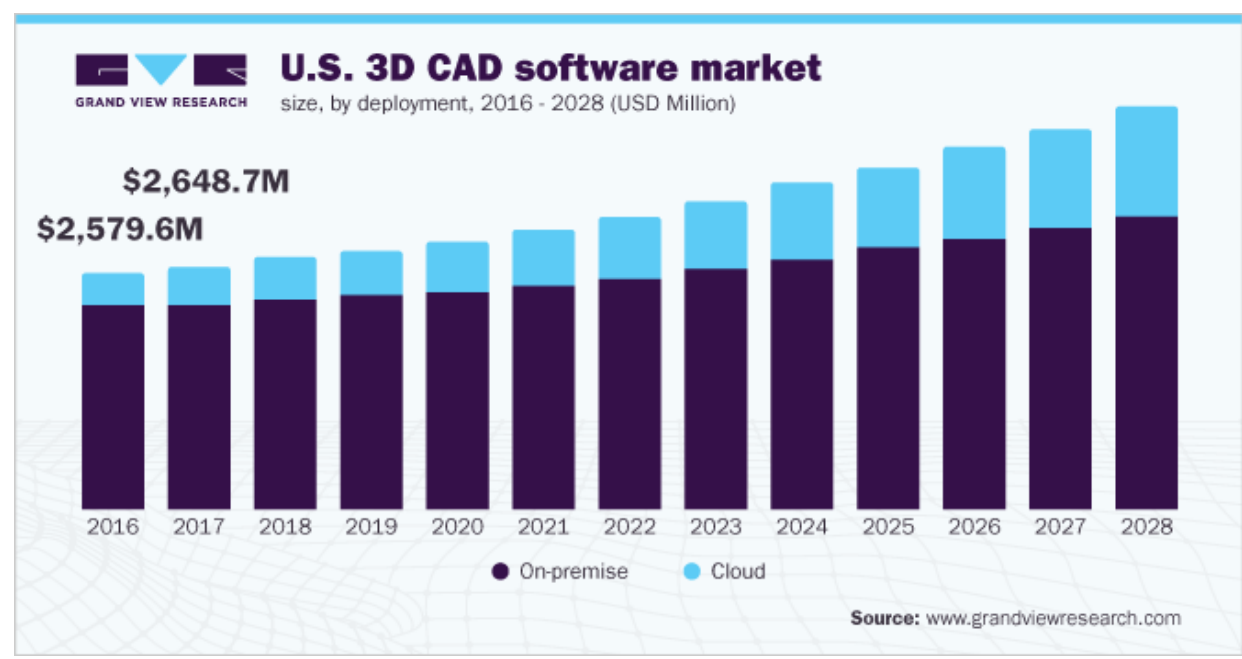

Рис. 5. Ринок програмного забезпечення для 3D CAD в США 
Потрібно зазначити, що з появою нових технологій, як до прикладу - VR (з англ. Virtual Reality - віртуальна реальність) перед нами відкриваються нові можливості під час проектування систем автоматизації. Оскільки VR дозволяє інженерам бачити, як їхні проекти будуть працювати в реальному світі і це є вагомим контраргументом для заощадження часу в своєчасному знаходженні дефектів та їх швидкому виправленні.

A віртуальна інженерія (virtual engineering) як імітаційний метод допомагає інженерам у прийнятті рішень та управлінні. Віртуальне середовище при цьому представлене обчислювальною структурою, що дозволяс точно імітувати геометричні й фізичні властивості реальних систем під час процесу проектування. При цьому береться концептуальний проект, а на виході виходять детальні конструкції компонентів або відсутні пророблені у всіх подробицях компоненти [10].

Висновки та майбутні перспективи. Можна дійти висновку, що існує безліч програм для проектування систем автоматизації. Всі вони мають свої переваги та недоліки. Для початку ознайомлення зі САПР доцільне застосування AutoCAd, який спрощує своє використання та надає більше можливостей для тестування, а в майбутньому - хмарних платформ.

\section{Список бібліографічного опису}

1. Тлумачний словник з інформатики / Г.Г. Півняк, Б.С. Бусигін, М.М. Дівізінюк, О.В. Азаренко, Л.М. Коротенко, Л.М. Коротенко. - Д., Нац.гірнич.ун-т. - 2010. - С.47

2. https://www.scan2cad.com/blog/cad/cad-evolved-since-1982/

3. https://www.autodesk.com/solutions/cad-blocks

4. Ihttps://www.magicad.com/ru/magicad-\%d0\%b4\%d0\%bb\%d1\%8f-revit-\%d0\%b8autocad/?utm_term=autodesk\&utm_campaign=MEP-NOB-

RU\&utm_source=adwords\&utm_medium=ppc\&hsa_acc=2111117430\&hsa_cam=9916233546\&hsa_grp=103366409427\& hsa_ad=432117242152\&hsa_src=g\&hsa_tgt=kwd-

10106226\&hsa_kw=autodesk\&hsa_mt=b\&hsa_net=adwords\&hsa_ver=3\&gclid=Cj0KCQiAy4eNBhCaARIsAFDVtI2iZjT nxSwmvHIbpW-ORgio5-Gd4iKNDUTIbJ-fUQ_WaPnRGGlyiQaAtjCEALw_wcB

5. https://csoftnw.ru/solutions/software/magicad_Truboprovody.html

6. https://www.zwsoft.ru/spds

7. https://soft.mydiv.net/win/download-LibreCAD.html

8. https://habr.com/en/post/425161/

9. https://www.grandviewresearch.com/industry-analysis/3d-cad-software-market

10. Кунву Ли. Основы САПР САD, САМ, САЕ. - СПб.: Питер, 2004. - С.436-461.

\section{References}

1. Explanatory Dictionary of Informatics / G.G. Pivnyak, BS Busygin, MM Divizinyuk, OV Азаренко, Л.М. Коротенко, Л.M. Korotenko. - D., Nats. hirnych. un-t, 2010. - P.47

2. https://www.scan2cad.com/blog/cad/cad-evolved-since-1982/

3. https://www.autodesk.com/solutions/cad-blocks

4. https://www.magicad.com/ru/magicad-\%d0\%b4\%d0\%bb\%d1\%8f-revit-\%d0\%b8autocad/?utm_term=autodesk\&utm_campaign=MEP-NOB-

RU\&utm_source=adwords\&utm_medium=ppc\&hsa_acc=2111117430\&hsa_cam=9916233546\&hsa_grp=103366409427\& hsa_ad $=432117242152 \&$ hsa_src $=g \& h s a \_t g t=k w d-$

10106226\&hsa_kw=autodesk\&hsa_mt=b\&hsa_net=adwords\&hsa_ver=3\&gclid=Cj0KCQiAy4eNBhCaARIsAFDVtI2iZjT nxSwmvHIbpW-ORgio5-Gd4iKNDUTIbJ-fUQ_WaPnRGGlyiQaAtjCEALw_wcB

5. $\quad$ https://csoftnw.ru/solutions/software/magicad_Truboprovody.html

6. https://www.zwsoft.ru/spds

7. https://soft.mydiv.net/win/download-LibreCAD.html

8. https://habr.com/en/post/425161/

9. https://www.grandviewresearch.com/industry-analysis/3d-cad-software-market

10. Kunvu Ly. Osnovy SAPR CAD, CAM, CAE. - SPb.: Pyter, 2004. - P.436-461. 